\title{
Effect of local insulin injection on wound vascularization in patients with diabetic foot ulcer
}

\author{
ZHAOXIN ZHANG and LEI LV \\ Department of Burns, People's Hospital of Xinjiang Uygur Autonomous Region, \\ Urumchi, Xinjiang Uygur Autonomous Region 830001, P.R. China
}

Received October 14, 2014; Accepted September 1, 2015

DOI: $10.3892 /$ etm.2015.2917

\begin{abstract}
The aim of the present study was to investigate the effect of local insulin injection on granulation tissue formation in the wounds of patients with diabetic foot ulcer. Thirty-two patients with diabetic foot ulcer were randomly divided into an insulin $(n=18)$ and a control $(n=14)$ group. In the diabetic foot ulcer wound, the insulin group were administered insulin and the control group were administered an equal volume of saline. Prior to injection and at 0.5, 1.0, 2.0 and $4.0 \mathrm{~h}$ after injection, the fingertip blood glucose levels were determined. The growth of granulation tissue was assessed continuously for 12 days. Wound tissue was harvested at $0,5,7$ and 12 days for the detection of CD34 expression by immunohistochemistry. The microvessel density (MVD) was calculated. No significant difference in the fasting blood glucose level was found between the two groups at any time-point $(\mathrm{P}>0.05)$. Growth of granulation tissue in the insulin group was more marked from 7 days after local insulin injection $(24.87 \pm 0.24)$ and was significantly different from that in the control group $(18.66 \pm 0.45)(\mathrm{P}<0.01)$. New vessels were observed in the insulin group 3 days after insulin injection; however, there was no significant difference in MVD compared with the control group $(\mathrm{P}>0.05)$. The MVD in the insulin group increased markedly from 5 days after treatment, and the difference between the two groups was significant $(\mathrm{P}<0.01)$. In conclusion, local injection of insulin into the base of a diabetic foot ulcer has a significant effect on systemic blood glucose and may promote wound healing by improving the growth of granulation tissue.
\end{abstract}

\section{Introduction}

Diabetic foot is a common complication of diabetes. In patients with diabetic foot ulcers, numerous factors can lead

Correspondence to: Dr Zhaoxin Zhang, Department of Burns, People's Hospital of Xinjiang Uygur Autonomous Region, 91 Tianchi Road, Urumchi, Xinjiang Uygur Autonomous Region 830001, P.R. China

E-mail: sskzzx@126.com

Key words: diabetic foot, insulin, wound healing to the slow growth of the local wound granulation tissue, such as increased blood glucose (locally and systemically), inefficient wound angiogenesis and fibrous tissue deposition $(1,2)$. Clinical and animal experiments have indicated that local treatment with insulin may improve wound healing in diabetes (3-5). A previous animal study demonstrated that insulin could reduce inflammation and increase collagen deposition, thus inducing accelerated burn wound healing (6). In addition, insulin injected diffusely into the wound can accelerate wound re-epithelialization (7-10). This may be caused by insulin promoting protein synthesis and suggests that insulin may play a role in the process of wound healing. Local use of insulin in the treatment of refractory wounds has been widely studied; however, the effective concentration and the safe dose of insulin are not clear.

The disorder and loss of function of angiogenesis in diabetic ulcer wounds are considered to be the dominating factors leading to poor wound healing (11-13). Restoring the function and structure of the vasculature and improving angiogenesis are currently the key problems to be solved for wound healing in patients. CD34 is a type-I phosphorylated transmembrane glycoprotein and a marker of vascular endothelial cells. Due to its high expression levels in new blood vessels, CD34 is additionally an important indicator of angiogenesis. Anti-CD34 antibody can be used to successfully distinguish new blood vessels from mature vessels (14). Microvessel density (MVD), which is calculated based on the expression of CD34, represents a quantitative indicator of angiogenesis. As a result, curative effects in cases of diabetic foot can be assessed by detecting the expression of CD34 and calculating the MVD.

The aim of the present study was to investigate the effect of local insulin injection on granulation tissue formation in the wounds of patients with diabetic foot ulcer. The curative effects and safe dose of local insulin injection were also evaluated.

\section{Materials and methods}

Patients. The 32 patients enrolled in this study were hospitalized in the Department of Burns of the People's Hospital of Xinjiang Uygur Autonomous Region (Urumchi, China) between June 2010 and June 2013. Among these patients were 22 men and 10 women. The age of the patients ranged from 42 to 83 years, with the mean age of $67.12 \pm 2.65$ years. 
The patients all had diabetes, and the duration of diabetes was $5-20$ years (mean, $7.52 \pm 1.33$ years). The fasting fingertip blood glucose level, as determined by the OneTouch ${ }^{\circledR}$ blood glucose meter (Johnson \& Johnson, Rochester, NY, USA), ranged from 5.7 to $8.6 \mathrm{mmol} / 1$ (mean, $6.66 \pm 1.19 \mathrm{mmol} / \mathrm{l}$ ). The duration of ulcers (gangrene) was 12-160 days (mean, $122.36 \pm 34.5$ days). Certain cases were complicated by diabetic nephropathy, retinopathy and cardiovascular disease (such as coronary heart disease, hypertension and cerebral infarction). The inclusion criteria for the patients were as follows: i) Patients who were diagnosed with diabetic foot according to the 2010 Edition of the Clinical Practice Guidelines for the Prevention and Management of Diabetes Foot Complications (edited by the American Diabetes Association) (6); ii) voluntary participants who were able and willing to participate in the study; iii) patients who had relatively stable blood glucose levels, without the influence of diet, exercise, infection, stress or other factors that could affect systemic blood glucose; and iv) patients who exhibited yellow wounds without significant growth of granulation tissue. The exclusion criteria were as follows: i) Patients who succumbed during the treatment; ii) patients who exhibited extensive and complete necrosis in the body and required immediate amputation at the time of admission to hospital; iii) patients who were discharged early or discontinued the therapy. Six patients were excluded from the present study. Written informed consent was obtained from all patients enrolled in the study prior to them undergoing the examination. The study protocol was approved by the Ethics Committee of the People's Hospital of Xinjiang Uygur Autonomous Region.

Wound treatment. The eschar and necrotic tissue attached to the wound was removed. As a support for late repair, the tendons and nerves without obvious liquefactive necrosis were reserved, and soft tissues were retained to the greatest extent possible. To avoid the effect of the drug on the local blood glucose level, all the wounds were cleaned with physiological saline.

Grouping and sample collection. The 32 patients enrolled in this study were randomly allocated to either the insulin group $(n=18)$ or the control group $(n=14)$. In the insulin group, one-half of the calculated dose of isophane protamine biosynthetic human insulin (premixed 30:70; Novo Nordisk Pharmaceutical Industries, Inc., Clayton, NC, USA) was diluted with physiological saline to a total volume of $1 \mathrm{ml}$ and was then injected diffusely into the base of the diabetic foot ulcer. The remaining half dose of insulin was subcutaneously injected into the abdominal wall. The insulin injection was performed twice a day. In the control group, the calculated dose of human insulin was subcutaneously injected into the abdominal wall and $1 \mathrm{ml}$ normal saline was subcutaneously injected into the base of the diabetic foot ulcer. The injection was performed twice a day. Both groups received injections for 7 consecutive days.

On days $0,5,7$ and 12 after injection, wound tissue measuring $0.5 \times 0.5 \mathrm{~cm}$ was collected from each patient. The wound tissues were fixed with $10 \%$ formaldehyde for immunohistochemical assay. The observation period ended 12 days after injection.
Blood glucose measurement. Following debridement, the fasting fingertip blood glucose levels of the two groups were measured using the OneTouch blood glucose meter (Johnson \& Johnson). At 0.5, 1.0, 2.0 and $4.0 \mathrm{~h}$ after injection each day, the fasting fingertip blood glucose levels of the two groups were also determined, and the measurements and injections were conducted for 7 days.

Granulation tissue assessment. The degree of granulation tissue growth was evaluated according to a method described in a previous study (15). Briefly, prior to treatment, the original ulcer wound areas of the two groups were recorded using transparent tracing paper. The wound size was traced with the same method following treatment. The growth of the granulation tissue was calculated using Photoshop CS 8.0 software (Adobe Systems, Inc., San Jose, CA, USA). The formula used was as follows: Granulation tissue growth $=($ Original wound area - wound area without granulation coverage)/original wound area $\mathrm{x} 100 \%$.

Immunohistochemical staining. All specimens were fixed with $10 \%$ paraformaldehyde for $48 \mathrm{~h}$ and embedded in paraffin. Paraffin-embedded tissue was sliced continuously into $4-\mu \mathrm{m}$ sections and stained with hematoxylin and eosin. To achieve this, slides were deparaffinized and rehydrated. Endogenous peroxidase was blocked with $3 \%$ hydrogen peroxide in methanol for $10 \mathrm{~min}$ at $37^{\circ} \mathrm{C}$. Subsequently, the sections were washed with distilled water, and antigen retrieval was performed by boiling with antigen retrieval solution (GeneTex, Inc., Irvine, CA, USA for 1-4 min. Nonspecific binding was blocked by incubating the slides with goat serum for $30 \mathrm{~min}$ at $37^{\circ} \mathrm{C}$. Primary rabbit anti-CD34 antibody (1:500; cat. no. D\&M-2038R: Beijing Bioss Biological Technology Co., Ltd., Beijing, China) was added for incubation overnight at $4^{\circ} \mathrm{C}$. The sections were then washed with Tris-buffered saline containing $0.1 \%$ Tween and incubated with biotin-labeled secondary antibodies for $30 \mathrm{~min}$ at room temperature, and horseradish peroxidase-labeled streptavidin was added for incubation for $30 \mathrm{~min}$ at $37^{\circ} \mathrm{C}$. Immunoreactivity was visualized using the chromogen 3,3'-diaminobenzidine and terminated with distilled water. The sections were then counterstained with hematoxylin, differentiated with hydrochloric acid ethanol, dehydrated with gradient alcohol and xylene and mounted onto coverslips. In the negative control, phosphate buffer was used instead of the primary antibody. Samples were observed under a light microscope. Cells with brown staining in the cytoplasm, the nucleus or both were considered to be positive. The Axioskop 2 Plus microscopy and image analysis system (Carl Zeiss Microscopy GmbH, Jena, Germany) was used for the analysis of CD34 expression, and the method of Pareek et al (14) was used for MVD calculation. Briefly, at each time-point, 3 sections per groups were taken and observed under the microscope. Cells with brown granules were considered to be positive for CD34. Brown-stained single endothelial cells or cell clusters were considered as a vessel count. The 3 regions with highest MVD at low magnification (x40) and 5 regions with the highest MVD at high magnification (x200) were taken and the average number was used as the MVD value. 
Table I. Changes in the fingertip blood glucose level in the two groups prior to and following insulin injection.

\begin{tabular}{lcccr}
\hline & & \multicolumn{3}{c}{ Blood glucose after insulin injection (mmol/l) } \\
\cline { 3 - 5 } Group & $\begin{array}{c}\text { Blood glucose before } \\
\text { insulin injection (mmol/l) }\end{array}$ & $0.5 \mathrm{~h}$ & $1.0 \mathrm{~h}$ & $2.0 \mathrm{~h}$ \\
\hline Insulin, $\mathrm{n}=18$ & $11.38 \pm 0.96^{\mathrm{a}}$ & $\begin{array}{c}11.06 \pm 0.65^{\mathrm{b}} \\
9.34 \pm 0.19\end{array}$ & $\begin{array}{c}9.76 \pm 0.57^{\mathrm{c}} \\
9.28 \pm 0.27\end{array}$ & $\begin{array}{c}6.65 \pm 0.18^{\mathrm{d}} \\
6.66 \pm 0.30\end{array}$ \\
Control, $\mathrm{n}=14$ & $12.06 \pm 0.61$ & $\begin{array}{l}11.51 \pm 0.26^{\mathrm{e}} \\
11.49 \pm 0.32\end{array}$ \\
\hline
\end{tabular}

Data are presented as the mean \pm standard deviation. Compared with the control group: ${ }^{a} \mathrm{P}=0.140$ and $\mathrm{t}=1.834 ;{ }^{\mathrm{b}} \mathrm{P}>0.999$ and $\mathrm{t}=0.000 ;{ }^{\mathrm{c}} \mathrm{P}=0.092$ and $\mathrm{t}=2.209 ;{ }^{\mathrm{d}} \mathrm{P}=0.971$ and $\mathrm{t}=0.038 ;{ }^{\mathrm{e}} \mathrm{P}=0.938$ and ${ }^{\mathrm{e}} \mathrm{t}=0.082$.

Table II. Comparison of the growth of granulation tissue in the two groups.

\begin{tabular}{|c|c|c|c|c|}
\hline Group & 0 days $(\%)$ & 5 days $(\%)$ & 7 days $(\%)$ & 12 days $(\%)$ \\
\hline Insulin, $\mathrm{n}=18$ & $7.45 \pm 0.18^{a}$ & $13.38 \pm 0.36^{\mathrm{b}}$ & $24.87 \pm 0.24^{c}$ & $59.06 \pm 1.58^{\mathrm{d}}$ \\
\hline Control, $n=14$ & $8.20 \pm 0.28$ & $12.98 \pm 0.45$ & $18.66 \pm 0.45$ & $23.61 \pm 1.57$ \\
\hline
\end{tabular}

Data are presented as the mean \pm standard deviation. Compared with the control group: ${ }^{\mathrm{a}} \mathrm{P}=0.259$ and $\mathrm{t}=1.274 ;{ }^{\mathrm{b}} \mathrm{P}=0.163$ and $\mathrm{t}=1.634 ;{ }^{\mathrm{c}} \mathrm{P}<0.001$ and $\mathrm{t}=24.246 ;{ }^{\mathrm{d}} \mathrm{P}<0.001$ and $\mathrm{t}=17.420$.

Table III. Comparison of microvessel density in the two groups at different time-points (number/HP).

\begin{tabular}{lccrr}
\hline Group & 0 days & 5 days & 7 days & 12 days \\
\hline Insulin, $\mathrm{n}=18$ & 0 & $3.45 \pm 0.19^{\mathrm{a}}$ & $8.34 \pm 0.48^{\mathrm{b}}$ & $11.22 \pm 0.97^{\mathrm{c}}$ \\
Control, $\mathrm{n}=14$ & 0 & $3.43 \pm 0.14$ & $4.42 \pm 0.14$ & $5.44 \pm 1.13$
\end{tabular}

Data are presented as the mean \pm standard deviation. Compared with the control group: ${ }^{\mathrm{a}} \mathrm{P}=0.815$ and $\mathrm{t}=0.247 ;{ }^{\mathrm{b}} \mathrm{P}<0.001$ and $\mathrm{t}=16.568$; ${ }^{\mathrm{c}} \mathrm{P}<0.001$ and $\mathrm{t}=27.664$. HP, high power field.

Statistical analysis. The statistical analyses were performed using SPSS version 10.0 (SPSS Inc., Chicago, IL, USA) for Windows. The t-test was conducted to calculate the statistical significance between the groups. $\mathrm{P}<0.01$ was considered to indicate a statistically significant difference.

\section{Results}

Changes in fingertip blood glucose levels in the groups at different time-points after insulin injection. To determine the effect of local insulin injection on the systemic blood, fingertip blood glucose detection was performed. As shown in Table I, the fasting blood glucose levels in the two groups were maintained at 6.7-12.1 mmol/1 (mean 9.95 $2.21 \mathrm{mmol} / \mathrm{l})$ before and after insulin injection. No significant difference in blood glucose level was found between the two groups before the injection or at $0.5,1.0,2.0$ and $4.0 \mathrm{~h}$ after injection. Local insulin injection in the wound had a marked effect on the systemic blood glucose levels: The blood glucose showed a notable decrease 1-2 $\mathrm{h}$ after the injection of insulin and then gradually returned to the pre-injection level at $4 \mathrm{~h}$ after injection (Table I). This indicated that local wound insulin injection had a marked effect on systemic blood glucose and could achieve the purpose of lowering blood glucose.
The growth of granulation tissue. To assess the situation of wound angiogenesis, granulation tissue growth was examined. As shown in Table II, growth of granulation tissue in the insulin group was more marked on day 7 after injection (24.87 \pm 0.24$)$. Patients with this type of granulation tissue were ready to undergo surgical treatment. Compared with the control group at this time-point $(18.6 \pm 0.45)$, the growth in the insulin group was significantly different $(\mathrm{P}<0.01)$ (Figs. 1 and 2). This result indicated that the wound bed preparation time of the treatment group was shorter than that of the control group, and the wound healing of the treatment group was enhanced.

CD34 detection and MVD counting. To assess the curative effects of local insulin injection on diabetic foot, the expression of CD34 following insulin injection in the two groups was detected by immunohistochemistry, and the results are shown in Fig. 3. New vessels were observed in the insulin group at 5 days after insulin injection. The MVD was calculated as previously described. No significant difference in MVD was initially found between the two groups $(\mathrm{P}>0.05)$ (Table III). In the insulin group, the MVD increased rapidly from 5 days after injection, and a significant difference was found between the two groups $(\mathrm{P}<0.01)$. This result indicated 

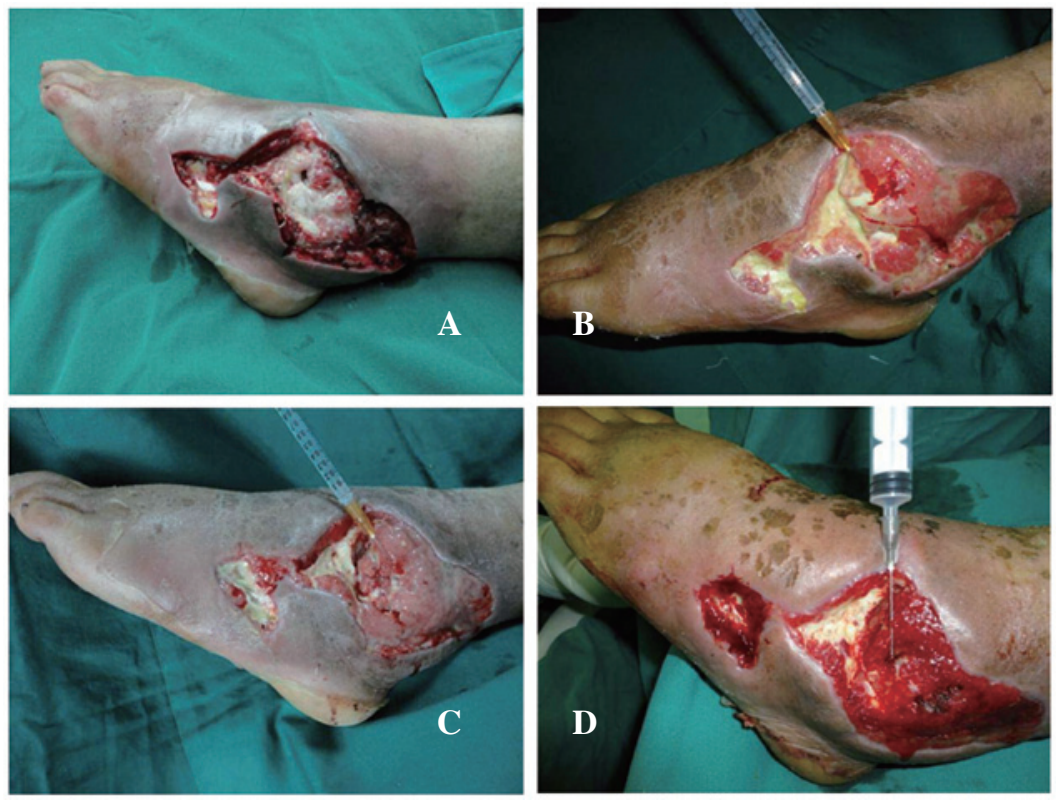

Figure 1. Observation of the diabetic foot of a patient in the insulin treatment group. The patient was male, aged 65 years and had a 28 -year history of diabetes. The wound in his left foot did not heal for 3 weeks. (A) The wound, which was level with the 4th and 5th toes of the left foot, following the debridement of necrotic tissue. (B) After 5 days of local insulin injection, the necrotic tissue became partially desquamated and granulation tissue began to grow. (C) After 7 days of local insulin injection, the necrotic tissue became mostly desquamated and the granulation tissue grew well. (D) After 12 days of local insulin injection, the joint cavity closed completely. The granulation tissue grew well and the wound bed was perfectly suited for surgery.
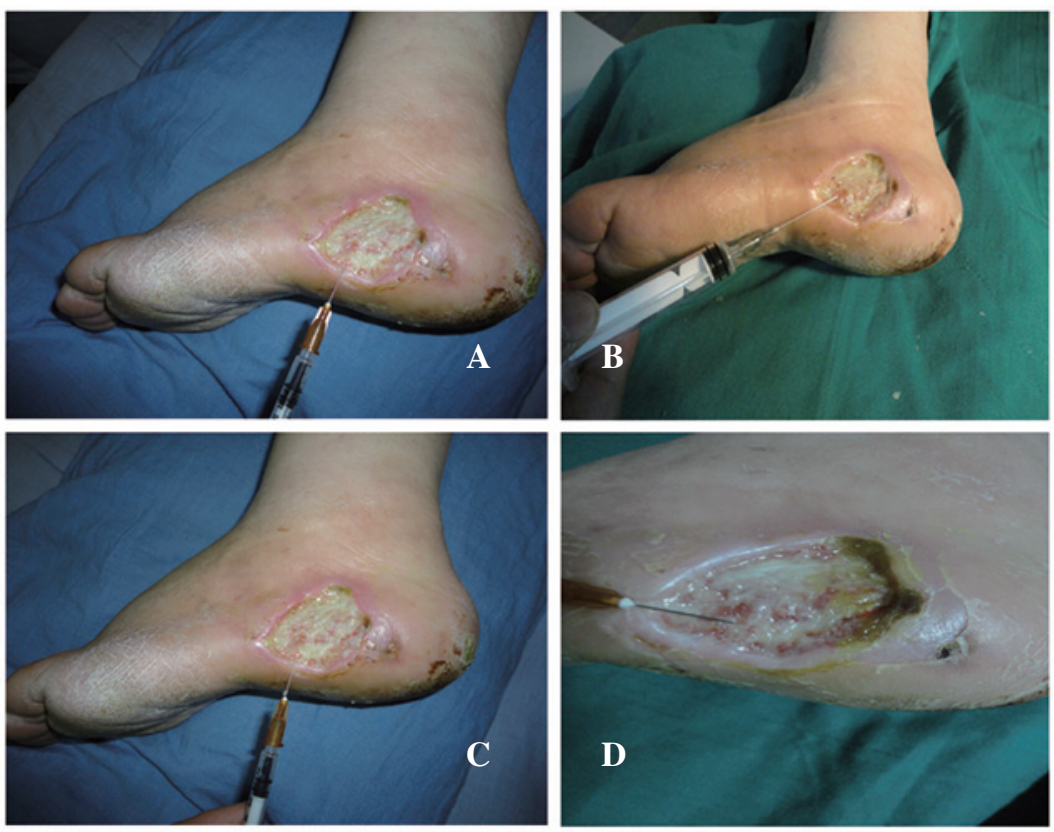

Figure 2. Observation of the diabetic foot of a patient in the control group. This patient was male, aged 68 years and had a 30-year history of diabetes. The wound in his left foot did not heal for 3 weeks. (A) The wound in the left heel following the debridement of the necrotic tissue. (B-D) Appearance of the wound after (B) 5 days, (C) 7 days and (D) 12 days of local injection of normal saline.

that the local injection of insulin in diabetic foot ulcers could promote the growth of granulation tissue.

\section{Discussion}

Insulin has numerous functions, such as protection of the vascular endothelium, vascular dilation, myocardial protection and anti-platelet aggregation and anti-atherosclerosis effects $(16,17)$. The local use of insulin (local wet dressing or injection) is reported to be effective in the treatment of refractory diabetic wounds (5); however, the results have been obtained in animal experiments and the insulin doses used lack a theoretical basis (18). Thus, the safety of the local use of insulin in humans is not clear. Obstructive factors, such as the poor permeability of insulin, wound surface exudation and tissue necrosis, make it difficult for insulin wet packing to achieve the desired effect. Local injection of insulin in the local wound is more effective due to its maintenance of a high 
A

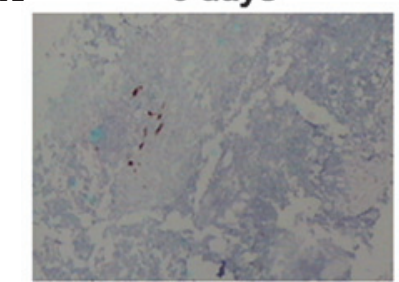

B

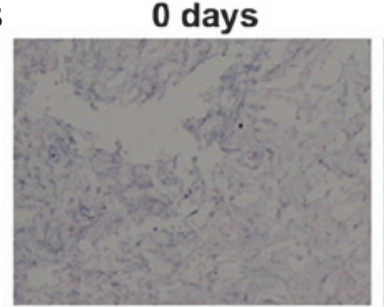

5 days

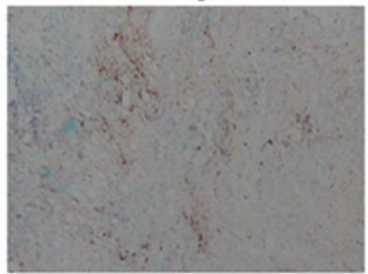

5 days

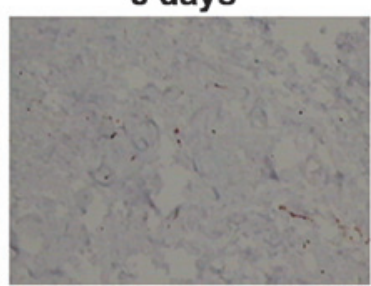

7 days

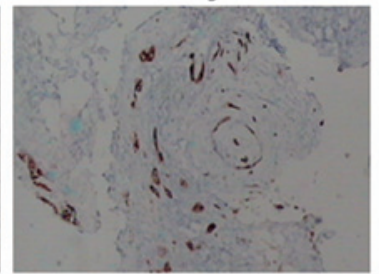

7 days

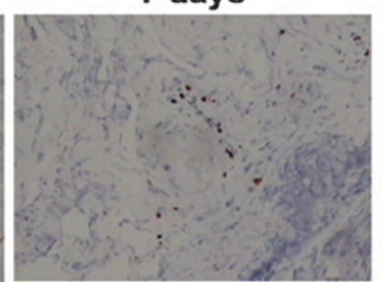

12 days

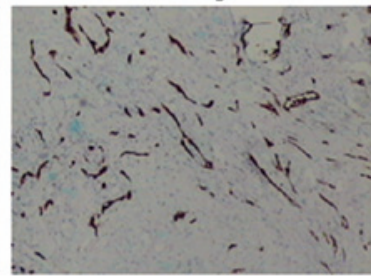

12 days

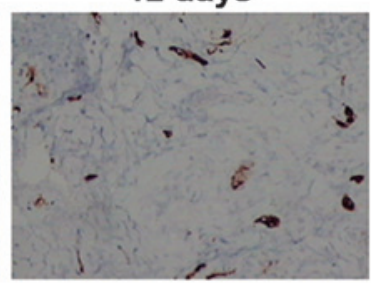

Figure 3. CD34 expression analysis by immunohistochemical staining. Results for the immunohistochemistry staining of CD34 at 0, 5, 7 and 12 days after local insulin injection are shown (magnification, x100). (A) Insulin group. (B) Control group.

concentration and its long duration of efficacy. In the present study, the blood glucose level decreased significantly $1-2 \mathrm{~h}$ after the injection of one-half the calculated dose of insulin. Two patients showed symptoms of hypoglycemia, including palpitations, dizziness, pale appearance and cold sweats. The result demonstrated that the local injection of insulin into the wound could reduce the body blood glucose, similar to other clinical treatments, and the injection had a marked effect on the systemic blood glucose. This result also suggested that local use of insulin should be individualized, in case of the onset of systemic hypoglycemia.

The occurrence of diabetic foot is a consequence of multiple factors, such as high glucose levels, vascular disease, neuropathy and infections (19). Currently, the establishment of an animal model of diabetic foot is not completely successful. Diabetic angiopathy is a manifestation of diabetic foot, and the artery system is the most commonly affected organ (20). The manifestations in the affected artery system show as plaque, intimal thickening, stenosis and occlusion. The vein and lymphatic systems are often normal or with minor disease signs, without obvious obstacles in local limb blood flow. As a result, the insulin that is locally injected into the ulcer wound can be absorbed into the blood circulation perfectly, as if it were injected into other parts of the body. Insulin plays the role of lowering blood glucose, which may underlie the effect of the local injection of insulin on systemic blood glucose $(21,22)$.

The results of the present study showed that at 5 days after local insulin injection, the expression of CD34 and the MVD in the insulin group began to increase; however, compared with the control group, there was no significant difference in MVD (P>0.05). Furthermore, no significant difference was found in the granulation tissue growth between the two groups. Growth of granulation tissue in the insulin group was more marked on day 7 after injection $(24.87 \pm 0.24)$. The necrotic tissue had been shed, and partially exposed bone and tendon had become gradually covered by granulation tissue. These represented essential processes for wound bed preparation. The MVD of the insulin group showed a rapid increase at day $7(8.34 \pm 0.48)$, which showed the consistency of the histology and gross observation results.
The biological effects of local insulin injection have been suggested to be associated with several molecular mechanisms. First, insulin reduces the local wound blood glucose concentration, thus reducing the damage resulting from the accumulation of high levels of glucose metabolic intermediates (21). Secondly, insulin is the inhibitor of three major proinflammatory transcription factors: Nuclear factor- $\kappa B$, activator protein-1 and early growth response-1 (EGR-1). The expression of regulating monocyte chemotactic protein 1 , intercellular adhesion molecule-1, matrix metalloproteinase (MMP)-2, MMP-9, tissue factor and plasminogen activator inhibitor-1, which are regulated by these three transcription factors, is also inhibited by insulin $(23,24)$. These proteins are important components of NADPH oxidase, which produces superoxide radicals with potent oxidative effects (23-26), leading to the damage of the tissue cells. In addition, insulin inhibits the transcription of three key proinflammatory factors induced by hyperglycemia, thus inhibiting the inflammatory response and local oxidative stress $(25,27)$. A third potential mechanism is that, by reducing the inflammatory cell factor level and increasing the inflammatory cytokine level following trauma, insulin relieves the inflammatory response and prevents an excessive inflammatory reaction (3). Furthermore, insulin inhibits the degradation of immune cell proteins, thus enhancing immune activity (3). Another mechanism has been suggested to involve the insulin-induced entry of extracellular amino acids and $\mathrm{K}^{+}$into the cells, which increases protein synthesis (28), greatly reduces the bacterial survival environment, enhances the ability of local inflammation and thus promotes local wound healing. Insulin additionally increases the synthesis and release of nitric oxide (NO). Endothelial NO plays an important role in neovascularization. Neovascularization is promoted by vascular endothelial growth factors (VEGFs), while VEGF promotes angiogenesis (29). Finally, insulin can activate myofibroblasts, advance the cell cycle and promote collagen deposition, thus accelerating the wound healing process.

In the present study, it was found that local wound insulin injection could reduce the blood glucose level, suggesting a 
significant effect on systemic blood glucose by local injection. These results provided the theoretical basis for treatment of diabetic foot via local insulin injection; however, the association between the dosages of insulin and the growth of granulation tissue, together with the exact mechanism of this action, remains to be investigated further.

\section{Acknowledgements}

This study was supported by a program of the Natural Science Foundation Committee of Xinjiang Uygur Autonomous Region (no. 2012211A090).

\section{References}

1. Aalaa M, Malazy OT, Sanjari M, Peimani $M$ and Mohajeri-Tehrani M: Nurses' role in diabetic foot prevention and care; a review. J Diabetes Metab Disord 11: 24, 2012.

2. Alavi A, Sibbald RG, Mayer D, Goodman L, Botros M, Armstrong DG, Woo K, Boeni T, Ayello EA and Kirsner RS Diabetic foot ulcers: Part II. Management. J Am Acad Dermatol 70: 21, 2014.

3. Madibally SV, Solomon V, Mitchell RN, Van De Water L, Yarmush ML and Toner M: Influence of insulin therapy on burn wound healing in rats. J Surg Res 109: 92-100, 2003.

4. Lima MH, Caricilli AM, de Abreu LL, Araújo EP, Pelegrinelli FF, Thirone AC, Tsukumo DM, Pessoa AF, dos Santos MF, de Moraes MA, et al: Topical insulin accelerates wound healing in diabetes by enhancing the AKT and ERK pathways: A double-blind placebo-controlled clinical trial. PLoS One 7: e36974, 2012.

5. Martínez-Jiménez MA, Aguilar-García J, Valdés-Rodríguez R, Metlich-Medlich MA, Dietsch LJ, Gaitán-Gaona FI, Kolosovas-Machuca ES, González FJ and Sánchez-Aguilar JM: Local use of insulin in wounds with diabetic patients: Higher temperature, fibrosis, and angiogenesis. Plast Reconstr Surg 32 1015 e-1019e, 2013

6. American Diabetes Association: Standards of medical care in diabetes - 2010. Diabetes Care 33 (Suppl 1): S11-S61, 2010.

7. Zhang XJ, Chinkes DL, Sadagopa Ramanujam VM and Wolfe RR: Local injection of insulin-zinc stimulates DNA synthesis in skin donor site wound. Wound Repair Regen 15: 258-265, 2007.

8. Zhang XJ, Wu X, Wolf SE, Hawkins HK, Chinkes DL and Wolfe RR: Local insulin-zinc injection accelerates skin donor site wound healing. J Surg Res 142: 90-96, 2007.

9. Liu Y, Zhang X, Zhang Z, Fang PY and Xu WS: Effects of topical application of insulin on the wound healing in scalded rats. Zhonghua Shao Shang Za Zhi 20: 98-101, 2004 (In Chinese).

10. Liu Y,Zhang X,Zhang Z and Xu WS: The influence of topical application of insulin on the formation of basement membrane in scalded rats. Zhonghua Shao Shang Za Zhi 21: 445-447, 2005 (In Chinese).

11. Schramm JC, Dinh T and Veves A: Microvascular change in the diabetic foot. Int J Low Extrem Wounds 5: 149-159, 2006.

12. Martin A, Komada MR and Sane DC: Abnormal angiogenesis in diabetes mellitus. Med Res Rev 23: 117-145, 2003.

13. Cho CH, Sung HK, Kim KT, Cheon HG, Oh GT, Hong HJ, Yoo OJ and Koh GY: COMP-angiopoietin-1 promotes wound healing through enhanced angiogenesis, lymphangiogenesis and blood flow in a diabetic mouse model. Proc Natl Acad Sci USA 103: 4946-4951, 2006.
14. Pareek G, Shevchuk M, Armenakes NA, Vasjovic L, Hochberg DA, Basillote JB and Fracchia JA: The effect of finasteride on the expression of vascular endothelial growth factor and microvessel density: A possible mechanism for decreased prostatic bleeding in treated patients. J Urol 169: 20-23, 2003.

15. Li DL, Li QX and Peng DZ: Wound size measurement using digital camera and Photoshop software. Zhong Hua Shao Shang Za Zhi 26: 48, 2010 (In Chinese).

16. Dandona P, Mohanty P, Chaudhuri A, Garg R and Aljada A: Insulin infusion in acute illness. J Clin Invest 115: 2069-2072, 2005.

17. Langouche L, Vanhorebeek I, Vlasselaers D, Vander Perre S, Wouters PJ, Skogstrand K, Hansen TK and Van den Berghe G: Intensive insulin therapy protects the endothelium of critically ill patients. J Clin Invest 115: 2277-2286, 2005.

18. Zhang XJ, Meng C, Chinkes DL and Herndon DN: Beneficial effects of insulin on cell proliferation and protein metabolism in skin donor site wound. J Surg Res 168: e155-e161, 2011.

19. Adam KM, Mahmoud SM, Mahadi SI, Widatalla AH, Shawer MA and Ahmed ME: Extended leg infection of diabetic foot ulcers: Risk factors and outcome. J Wound Care 20: 440-444, 2011.

20. Abolfotouh MA, Alfaifi SA and Al-Gannas AS: Risk factors of diabetic foot in central Saudi Arabia. Saudi Med J 132: 708-713, 2011.

21. Zhang ZX, Liu XL, Lü L, Zhang L, Ji DL and Liu LH: Effect of insulin by local injection on the level of systemic blood glucose and granulation tissue formation of wound in patients with diabetic foot ulcer. Zhonghua Shao Shang Za Zhi 27: 451-455, 2011 (In Chinese).

22. Sinwar PD: The diabetic foot management - recent advance. Int J Surg 15: 27-30, 2015.

23. Dandona P, Aljada A, Mohanty P, Ghanim H, Hamouda W, Assian E and Ahmad S: Insulin inhibits intranuclear nuclear factor kappaB and stimulates IkappaB in mononuclear cells in obese subjects: Evidence for an anti-inflammatory effect? J Clin Endocrinol Metab 86: 3257-3265, 2001.

24. Aljada A, Ghanim H, Mohanty P, Kapur N and Dandona P: Insulin inhibits the pro-inflammatory transcription factor early growth response gene-1 (Egr)-1 expression in mononuclear cells (MNC) and reduces plasma tissue factor (TF) and plasminogen activator inhibitor-1 (PAI-1) concentrations. J Clin Endocrinol Metab 87: 1419-1422, 2002.

25. Chaudhuri A, Janicke D, Wilson MF, Tripathy D, Garg R, Bandyopadhyay A, Calieri J, Hoffmeyer D, Syed T, Ghanim H, et al: Anti-inflammatory and profibrinolytic effect of insulin in acute ST-segment-elevation myocardial infarction. Circulation 109: 849-854, 2004.

26. Aljada A, Ghanim H, Mohanty P, Syed T, Bandyopadhyay A and Dandona P: Glucose intake induces an increase in activator protein 1 and early growth response 1 binding activities, in the expression of tissue factor and matrix metalloproteinase in mononuclear cells, and in plasma tissue factor and matrix metalloproteinase concentrations. Am J Clin Nutr 80: 51-57, 2004.

27. Wang L, Zhao X, Wei BY, Liu Y, Ma XY, Wang J, Cao PC, Zhang Y, Yan YB, Lei W and Feng YF: Insulin improves osteogenesis of titanium implants under diabetic conditions by inhibiting reactive oxygen species overproduction via the PI3K-Akt pathway. Biochimie 108: 85-93, 2015.

28. Kimball SR, Vary TC and Jeferson LS: Regulation of protein synthesis by insulin. Annu Rev Physiol 56: 321-348, 1994.

29. Papapetropoulos A, García-Cardeña G, Madri JA and Sessa WC: Nitric oxide production contributes to the angiogenic properties of vascular endothelial growth factor in human endothelial cells. J Clin Invest 100: 3131-3139, 1997. 